\title{
Tarihi Değerlerinin Korunmasına ve Turizmin Gelişmesine Adanmış Örnek Bir Yaşam: Çelik Gülersoy
}

İstanbul'da birbiri ardına düzenlenip halka açılmış yeşil alanların, onarılıp fonksiyon verilmiş tarihsel yapıların, kültür alanında nice olumlu yankılar yaratmış çalışmaların, herbiri bir boşluğu doldurmuş yüzlerce kitabın ardında, sesiz sedasız işine bakmış, üretmiş bir kültür adamı... Yıllar boyu iğne ile kuyu kazar gibi kendini yetiştirmiş, birkaç bilim ve sanat dalında kaynaklara inecek kadar uzmanlaşmış ve derinleşmiş, turizm, hukuk, edebiyat, şehir ve sanat tarihi üzerine birçok özgün eserler vermiş bir araştırmac1yazar... Klasik Batı ve kendi müziğimizin tutkulu ve rafine bir izleyicisi, düzenlediği konserlerle bu güzellikleri toplumla paylaşmasını seven bir müzik dostu. Tabiatı ve tarihi çevreyi değerlendirmenin ve sanatı halka sunmanın (eğitici) kutsal bir iş olduğu inancıyla çalışmış, içi sevgiyle dolu bir gönül adamı. Doğu-Batı değerleri arasında başarılı sentezler ortaya koymuş bir öncü... Bütün olanaklarını İstanbul'un güzelleşmesi, eski ve asıl değerlerine kavuşması için seferber etmiş, doğaya tutkun bir İstanbul âşığı: Çelik Gülersoy. $\mathrm{Bu}$ yazıda kendisini tanıtmaya çalışacağım.

\section{YAŞAMI}

Çelik Gülersoy, babasının Doğu hizmeti sırasinda Hakkâri'de doğar (1930). Babası Akif Bey, Ünye'ye kadılar ve müftüler vermiş olan Müftüoğulları ailesindendir. Annesi Münevver Ha- nım ise, Erzurumludur. Aile, 1933 yılında Cumhuriyetin 10. yılı kutlama şenlikleri sırasında İstanbul'a gelerek önce Kariye Camii yakınında, 1934 yılından sonra ise Yıldız'da oturur. Gülersoy, ilk, orta ve lise öğrenimini İstanbul'da tamamlar. Beyoğlu Erkek Lisesi'ni birincilikle, İstanbul Hukuk Fakültesi'ni iyi derece ile bitirir. 1959-1960 yılları arasında askerlik görevini yapar. Öğrenimi sırasında girdiği Türkiye Turing ve Otomobil Kurumu'nun 1966 yılında da Genel Müdürü olur. Bu kuruluşu yeniden yapılandırarak ülkenin ihtiyaç duyduğu birçok hizmetleri kazandırır.

\section{ÇELIK GÜLERSOY'UN ALTIN YILLARI}

Gülersoy, İstanbul'daki ilk çevre düzenlemesini 1977 yılında Edirnekapısı'nda Kariye Camii ve çevresinde gerçekleştirir. 1979 yılı, başlattığ 1 büyük projelerle adının yurtiçinde ve yurtdışında duyulduğu dönemin başlangıcı olarak değerlendirilebilir. 1990 yılı ise, hükümetin triptik rejimini ansızın değiştirerek, Türkiye Turing ve Otomobil Kurumu'nun ana gelirini kesmesi aç1sindan olumsuz bir dönüm noktasıdır.

Gülersoy, 1979 yılında yayınladı̆̆ "Kapalıçarşı'nın Romanı" adlı kitabı ile Simavi Vakf1 ödülünü aldığg törende hazır bulunan Aytekin Kotil'in şehir konularında kendisinin fikirlerinden yararlanmak istediğini söyler. Bunun üze- 
rine Kotil ve yardımciları ile birlikte İstanbul'da bir gezi yaparlar. Gülersoy, Kotil'i Kariye Müzesi, Yıldız ve Emirgan parklarına götürür, harap durumdaki köşklerle, bakımsız parkları göstererek bir işbirliği teklifinde bulunur. Kurum, bütün Yıldız Parkı'nın bakımını üstüne alacak, birkaç köşkü onarıp halka açacak ve 15-20 yıl kullanıp karşılığında ayrıca kira da ödeyecek, parkın geliri de belediyeye kalacaktır. Restorasyon masrafları kiradan düşülmeyeceği gibi, ayrıca sigorta da yaptırılacaktır. Gülersoy'un sunduğu bütün şartlar, Belediye'nin dolayisıyla kamunun lehinedir. Kotil, iki sözleşmeyle bu tesisleri Kurum'a verdiğinde, Gülersoy da inanılmaz bir gayret ve beceri ile gece gündüz durup dinlenmeden uygulamalara girişir.

\section{MALTA KÖŞKÜ ILLE BAŞLAYAN BÜYÜK DÖNÜŞÜM}

1979 yılı başında Malta Köşkü'nün onarımı dört ay gibi kısa sürede bitirilip, binanın bütün odaları kısa sürede döşendiğinde ortaya çıkan sonuç herkesi şaşırtır. Malta Köşkü, Kurum'un organizasyonu olan uluslararası bir kongre ile açılır: Turing Kurumları (AIT) Uluslararası Federasyonu Avrupa Toplantısı. Reşit Saffet Bey'in 1930 yılında İstanbul'da topladığı bu önemli kongre, 49 yıl sonra yine İstanbul'da toplanmaktadır. Aynı yılın yazında, Yıldız Parkı'ndaki Çadır Köşkü'nün ön ve arka bahçeleri, Emirgan Parkındaki Sarı Köşk de, yine "sihirli bir değnek" değmişçesine yenilenerek halka açlır. Bu mekânlardaki olağanüstü değişimler hemen basının ilgisini çeker ve her cins yayın organında, bu yeni tesisleri tanıtan resim ve yazılar çıkmaya başlar.

1980 yılı yazında bu tesisleri gezen dönemin Kültür Bakanı Tevfik Koraltan da, Gülersoy’a Kültür Şeref Ödülü vermeyi kararlaştırır. Ödül töreni de Çadır Köşkü'nün bahçesinde yapılır. Çalışmalar yurtdışında da duyulmuş ve geniş yankı yaratır. Bunun sonucunda Avrupa Konseyi'ne bağlı bir kuruluş olan Europa Nostra Vakfı bile ilgi duyar ve kendi tarihinde ilk defa, Türkiye'ye bir ödül verir. Ödülün nedeni Malta Köşkü, sahibi de Gülersoy'dur. Bu gelişmelerin ardından, Fransız hükümeti de Gülersoy'a ulusal takdir nişanının "Officier" rütbesini verecek, töreni de Malta Köşkü'nde yapılacaktır.
Gülersoy'un Çamlıca Tepesi, Kariye, Yıldız ve Emirgan Parkları Düzenlemeleri Dünya çapında ün kazanır. Aynı süreçte Belediye Başkanı Aytekin Kotil, İstanbul, Kurum ve Gülersoy'un yaşamında çığır açacak önemli bir kararı Şehir Meclisi'nden geçirerek, Çamlıca Tepesi'nin düzenlenmesini Kurum'a verir. Şehir Meclisi'ndeki engellemelere karşın çıkan bu önemli karardan sonra gerçekten de kısa sürede Çamlıca Tepesi'nin çehresi inanılmaz şekilde değişir. Aylar sonra Gülersoy onu, görevinden ayrıldıktan sonra açılış törenine getirdiğinde, Kotil gördüğü manzara karşısında duygulanarak "bu kadarını ben de beklemiyordum..." diyecektir. Çamlıca düzenlemesi ile ilk kez, hem Kurum hem de Gülersoy, geniş halk kitleleriyle doğrudan iletişime geçer. Bir mezbeleliğin ve pislik yuvasının, kısa zamanda farklı bir yapıda düzenlenmesi ve buraya tarihi karakterde ulusal bir kimlik kazandırıması, bu konudaki yayınların yetersizliğine karşılık, halkın geniş ilgisini ve sevgisini çeker.

\section{ANADOLU UYGARLIKLARI BELGESELLERI VE YAYINLAR}

Açılışının duyulmasından sonra on binlerce insan burayı ziyarete gelir, tatil günlerinde, çevre trafiği uzun süre kilitlenir. Halkın bu olağanüstü ilgisi, o günlerde toplumda halk yararına yapılan olumlu hizmetlere duyulan samimi hasretin de bir göstergesidir. Bu arada Türkiye Turing ve Otomobil Kurumu'nun sponsorluğunda hazırlanan kültür filmleri dizisi Suha Arın'ın yönetimindeki yapımlarla birbiri ardınca devam etmekte, büyük beğeni ile tekrar tekrar gösterilmekte ve Antalya Festivali ödüllerini almaktadır.

İstanbul tarihi üstüne 1970'li yıllarda, bir seri halinde, şehrin semtlerinin yüzyıllar boyunca değişikliklerini saptayan gravür ve resim materyalini, semtlerin tarihçeleriyle beraber yayınlamaya başlar. İkinci bir dizi halinde ise, Türkiye'den bahseden birkaç ünlü batı eserlerini ilk defa olmak üzere dilimize kazandırarak, bunların başlarına, yazarlarının kimliğine dair etütler yazar. Üçüncü dizi olarak İstanbul'un semtleri ve önemli yapilarının monografilerini başlatır. Bu seride, Kapa1ı Çarşı'nın, Dolmabahçe ve Çırağan Saraylarının, Göksu'nun, Sultanahmet Camiinin ve Hıdiv Kasrı'nın, ilk kez yapılmış etütleri yayınlanır. 


\section{KAPIKULE DÜZENLENIYOR}

Kapıkule Gümrüğü'nün düzenlenmesi de 1981 yılında tamamlanır. O güne kadar tam bir kargaşa görünümündeki Türkiye'nin bu en büyük kapısı, tanınmaz derecede düzeltilir, 70 dönümlük bir arazi ele alınarak modern bir görünüm kazandırılır. Buna karşılık açılış töreninde, Kurum'a yer verilmediği gibi Gülersoy'a da konuşma hakkı tanınmaz. Ancak olaya en geniş şekilde yer veren TV ve basin sayesinde, bu haksızlık, kamu vicdanında geniş yankılara yol açar. Bu bağlamda 1981 yılında askeri yönetim, gerçekd1şı iddialarla, Kurum aleyhinde bilgilendirilecek ve Kurum'un fonksiyonlarını Turizm Bankası'na devreden bir kanun hazırlattırılmaya bile çalışılacaktır.

Gülersoy, 1981 Atatürk Yılı'na anlam katan bir dizi hizmeti de gerçekleştirir. Büyük Ata'nın Samsun'a gitmeden önce 1919 yılında bir süre kaldığı Şişli'deki tarihi ev, kısa sürede Kurum kadroları seferber edilerek onarılır. Metnini kendisinin yazdığı ve Suha Arın'a hazırlattığı Dolmabahçe ve Atatürk belgeseli geniş ilgiyle izlenir. Eser, Güvenlik Konseyi'nin ve TRT'nin ilgisi ile 10 Kasım gecesi TRT televizyonunda gösterilir.

\section{YILDIZ PARKI PEMBE VE YEŞIL SERALARI}

Çelik Bey'in “İstanbul'u koruma ve güzelleştirme çalışmaları", 1980'li yıllarda peş peşe yine hizmetlerle her geçen gün artarak ve yankıları genişleyerek sürer. Yıldız ve Emirgan koruları içindeki restorasyon ve sıhhatleştirme programları sonucu; Beyaz Köşk, Pembe Köşk, Sarı Köşk, Malta Köşkü, Çadır Köşkü onarılarak, fonksiyon verilerek halka açılır. Yıldız Parkı'nda, Pembe ve Yeşil seralar Gülersoy'un çizgi ve yönlendirilmesiyle ile inşa edilerek farklı konseptlerle halkla buluşur. Çamlıca Tepesi'nde doğal çevre düzenlemeleriyle içinde çeşitli ünitelerden oluşan Osmanlı kahvehaneleri ve çiçekler dolusu bahçeler İstanbul'la birlikte tüm dünyanın ilgi odağı olur.

\section{SULTANAHMET'TE BIRR ÖNCÜ GIRIŞIM: YEŞiL EV}

Aynı zamanda müziğin duyarlı dostu olan Gülersoy'un, Beyaz Köşk'te düzenlendiği klasik müzik konserlerinin unutulmaz tadı izleyenlerin hafızalarındadır. 1983 yılında Ihlamur Mesiresi,
Kayıklar, İstanbul Estetiği kitaplarını yayınlar. 1984 yılında Sultanahmet'te otel olarak düzenlediği eski konak, Yeşil Ev adıyla bitirilerek açıldığında yurtiçinde ve dışında büyük yankı uyandırır. Bu öncü örnek tüm ülke çapında eski yapıların kaderini etkiyecektir. Aynı yıl Çubuklu'daki Hidiv Kasrı'nın da onarım ve restorasyon çalışmaları tamamlanır, içi döşenerek bahçesiyle birlikte halka açılır. 1984 yılında İstanbul'un Anıtsal Ağaçları ve Dolmabahçe kitaplarını yayınlar.

1985 yılında Kariye Müzesi karşısına tarihi tarzda bir pavyon yapılır ve buradaki meydan trafiğe kapatılarak korunmuş bir tarihi çevre oluşturulur. Aynı yıl, Hidivler ve Çubuklu Kasrı, Hotel d'Angleterre, Küçüksu ile Reklamlar ve Biz adlı eserlerini peş peşe yayımlar. 1985 yılında tüm mal varlığını, kendi adını taşıyan vakfa vasiyet yoluyla bırakır. 1986 yılında Ayasofya'nın yanındaki Soğukçeşme Sokağı'nda türünün öncü bir örneği olarak Ayasofya Pansiyonları'nın açılışını gerçekleştirir. Ayrıca Soğukçeşme Sokağı'nın içinde tamirhane olarak kullanılan antik sarnıç da onarılarak tipik bir restoran olarak düzenlenir. Aynı yıl Sultanahmet Konağı'nın yanındaki harap Cedid Mehmed Efendi Medresesi onarılarak İstanbul El Sanatları Çarşısı olarak fonksiyon kazandırılır. Şehir etütleri çalışmalarında İstanbul Şarkısı, Taksim, Soğukçeşme Sokağı kitaplarinı yayımlar.

1987 yılında Soğukçeşme Sokağı içindeki İstanbul Kitaplığı binası bitirilerek açılır. Kapıkule Gümrüğü arkasında 70 dönümlük bir alana Teknik ve Turistik Hizmet Merkezi kurulur. Soğukçeşme'de Soğukkuyu Medresesi'nin onarımına da destek verilir. Boğaz'ın karakteristik köşesi üzerine "Göksu'ya Ağıt" kitabını yayımlar. 1988 yılında şehir dışına taşınarak Zekeriyaköy'e yerleşir ve burası için kurduğu Vakıf ile köydeki birçok evin ve bahçenin ıslahını gerçekleştirir. 1989 y1lında “Tramvay İstanbul'da” ve tüm yaşamını konu alan "Kırk Yıl Olmuş" kitapları yayimlanir.

1990’1ı yılların başında Gülersoy yurtiçinde ve dışında herkesin yakından tanıdı̆̆ riyet Türkiye'sinin gerçek yıldızlarından, ülke kültürünün anıt isimlerinden birisidir. Ancak "Şark'ta" adet olduğu üzere her türlü sıra dı- 
Şı başarı ve toplum adına yapılan iyilikler onun açısından da bu ülkede cezasız kalmayacaktır. Fenerbahçe'nin imarı ile uğraşırken, belirli çevrelerin yönlendirmesiyle Özal hükümetinin Maliye Bakanlığı tarafından kurumun ana geliri kesilir. Böylece Gülersoy'un ve Kurum'un kamuya yönelik ve tüm ülkede büyük beğeni ve ilgi gören projelerinin engellenmesi süreci başlatılır. Kurum, bu sıkıntılı süreçte ülkeye kazandırdığı değerleri birbiri peşine elinden çıarmak zorunda kalır. Bolu Koru Oteli'ni, İstanbul'daki Kariye Oteli ve evlerini satar; 1974 yılından beri imar edip ve bakım altında tuttuğu Kariye de tümüyle elinden çıkar.

Tüm bu olumsuzluklara karşın eldeki k1sitlı olanaklarla yeni projelere devam eder. Fenerbahçe'de altı taş üstü cam büyük bir pavyon olan "Romantika" (1991), daha sonra Soğukçeşme Sokağı'nda konukevi ile Büyükdere'ye (1993) bir park yapar. Danıştay'ın içtihat değiştirmesi ile kurum 71 yıllık tarihinde ilk kez vergilendirilip, borcun geriye doğru işletilmesi üzerine kurum Şişli Meydanı'ndaki merkez binasını da satmak zorunda kalır (1994). Aynı yıl değişen Belediye yönetimi de Çamlıca'yı, Emirgan ve Yıldız Parkları dâhil tüm köşkleri Türkiye Turing ve Otomobil Kurumu'ndan geri alır. Tüm olumsuzluklara karşın Gülersoy, Büyükada için yeni bir proje başlatarak, belirli yerlerin onarımını sağlar, at arabaların ettirir (1996). Kargir ve harap Fabiato Köşkü tümden onarır, bahçesini yeniden düzenleyerek "Kültür Evi" adıyla kitaplık, konser salonu ve kafe olarak açar (1998).

Bu dönemde Büyükada'ya çekilmiş burada kendisine yeni projeler ve yayınlarla ayrı bir dünya kurmaya çalışır. Fenerbahçe Parkı'nda kurduğu Doğal Gıda Pazarında doğal ürünleri toplatıp halka sunar. Safranbolu'da "Cevizli Konak" otel olarak düzenlenir (2000). 2002 yılında Osmanlı'nın son dönem mimarisini yansıtan Büyükada İskelesi onarılarak, üst katında kurum tarafından işletilen bir kafe açılarak pusula, saat, eski haritalar gibi denizcilik materyalleri ve Şirket-i Hayriye'ye ait belgelerle donatılır. Büyükada Araba Meydanı düzenlenerek kontrol merkezi yapılır (2001). Eski Bebek İskelesi onarılır ve “Turing Bebek Cafe" olarak hizmete girer (2002).

\section{DEĞERLENDIRME VE SONUÇ}

İstanbul'un güzelleştirilmesi, tarihi eserlerin korunması ve turizmin geliştirilmesi konusunda gösterdiği örnek davranışın karşılığı olarak, 1999 yılında tahakkuk ettirilen "gecikme" cezalı ağır vergiler en verimli çağında elini kolunu bağlar (Danıştay'da üç kez kazanıldığı halde), siyasetin maruz biraktığ 1 haksızlıklar onu kahreder!... Bu olumsuz süreçte tutulduğu amansız hastalığın sonucu 5 Temmuz 2003 tarihinde Büyükada'da fenalaşmasının ardından kaldırıldığı Osmanoğlu Kliniği'nde 6 Temmuz günü vefat eder. 8 Temmuz Salı günü sevdikleri, dostları ve Türkiye Turing ve Otomobil Kurumu çalışanlarının katıldığ 1 bir törenle son yolculuğuna uğurlanarak, arzusu doğrultusunda çok sevdiği annesi Münevver Hanım'ın yanına, Demirciköy mezarlığında toprağa verilir. Mezarı daha sonra özel bir tasarımla düzenlenir. Kendisinin deyişiyle "Turing, tarihte ve ülkede bir ışıktı". Bu güçlü ışığın kaynağı ise, Çelik Gülersoy'un sevgi dolu benzersiz yüreği, iradesi ve eşsiz aklıdır. Aydınlık ve karanlığın ezeli mücadelesinde Cumhuriyet aydınlığının bu 1şık kaynağını, çok daha önemli eserler vereceğ $\mathrm{i}$ oldukça erken bir dönemde, içi ülke sevgisi dolu, kafasında gerçekleştiremediği hayalleriyle yitirdik...

\section{ESERLERI}

Gülersoy, Ç. (1955). Die Juristische Grundlage der Strossenverkehrsordung in der Türkei. İstanbul: Çituri Biraderler Basimevi.

Gülersoy, Ç. (1959). Tabiatı Koruma. İstanbul: Çituri Biraderler Basımevi.

Gülersoy, Ç. (1962). Beşiktaş'da Ihlamur Mesiresi ve Tarihi Kitabeler. İstanbul: Cesar Rigo Basımevi.

Gülersoy, Ç. (1962). Sosyal Turizm. İstanbul: Çituri Biraderler Basimevi.

Gülersoy, Ç. (1963). Trafik Polisinin İşaretleri: (Karşılaştırmalı Araştırma). İstanbul.

Gülersoy, Ç. (1964). Seyahat Acenteliği. İstanbul.

Gülersoy, Ç. (1964). Yillık Ücretli İzin. İstanbul.

Gülersoy, Ç. (1965). Türkiye'nin Turizm Propagandası. İstanbul.

Gülersoy, Ç. (1966). Un Guide d'İstanbul. İstanbul: İstanbul Matbaas1.

Gülersoy, Ç. (1966). Trafik'de Kılavuz Işsaretler. İstanbul: Yenilik Basımevi.

Gülersoy, Ç. (1966). Turizm Gerçĕ̆imizin En Önemli İncelemesi Üstüne Düşünceler. İstanbul: Yenilik Basımevi.

Gülersoy, Ç. (1967). A Guide to İstanbul. (Translated by Barry Unworth). İstanbul: Yenilik Basımevi. 
Gülersoy, Ç. (1967). Palast von Dolmabahçe = Palace of Dolmabahçe = Palais de Dolmahçe = Dolmabahçe Sarayı. İstanbul.

Gülersoy, Ç. (1968). Un guide d'İstanbul. İstanbul: Yenilik Basimevi.

Gülersoy, Ç. (1968). Führer durch İstanbul. İstanbul: Yenilik Basimevi.

Gülersoy, Ç. (1968). Otomobille Avrupa. Hazırlayanlar: Çelik Gülersoy, Fuat Ayantur, Oktay Alpin. İstanbul: Yenilik Basımevi.

Gülersoy, Ç. (1968). Yol ve Reklâmlar. İstanbul.

Gülersoy, Ç. (1970). Türk Toplumu ve Turizm: (Sosyo-Psikolojik Temeller). İstanbul: Yenilik Basımevi.

Gülersoy, Ç. (1970). Trafik Sorunumuz Üstüne Düşünceler. İstanbul: Yenilik Basımevi.

Gülersoy, Ç. (1971). Alphonse de Lamartine ve İstanbul Yazıları. İstanbul.

Gülersoy, Ç. (1971). Avrupa Gezi Rehberi. İstanbul.

Gülersoy, Ç. (1971). Menü. İstanbul.

Gülersoy, Ç. (1971). İstanbul: Köprü ve Galata. İstanbul.

Gülersoy, Ç. (1972). A Guide to İstanbul. İstanbul: Yenilik Basimevi.

Gülersoy, Ç. (1972). Turkish Society and Tourism: Historical and Socio-Psyhological Grounds. İstanbul.

Gülersoy, Ç. (1972). Korunması Gereken Boğaziçi. İstanbul.

Gülersoy, Ç. (1973). Führer Durch İstanbul. İstanbul: Yenilik Basımevi.

Gülersoy, Ç. (1973). Guide D'istanbul. İstanbul: Yenilik Bas1mevi.

Gülersoy, Ç. (1973). Türkiye Turing ve Otomobil Kurumu'nun 50 yılı (1923-1973). İstanbul.

Gülersoy, Ç. (1973). İstanbul: Tophane, Fındıklı, Kabataş. İstanbul.

Gülersoy, Ç. (1974). Kariye: (Chora). İstanbul.

Gülersoy, Ç. (1975). A Guide to İstanbul. İstanbul: Yenilik Basimevi.

Gülersoy, Ç. (1975). Guida di İstanbul. İstanbul: Yenilik Bas1mevi.

Gülersoy, Ç. (1975). Otomobil İle Avrupa Gezi Rehberi. İstanbul.

Gülersoy, Ç. (1975). Kariye: Chora. İstanbul.

Gülersoy, Ç. (1976). A guide to İstanbul. İstanbul: Yenilik Basimevi.

Gülersoy, Ç. (1976). Guiede d'İstanbul. İstanbul: Yenilik Bas1mevi.

Gülersoy, Ç. (1976). Batıya Doğru. İstanbul.

Gülersoy, Ç. (1977). Führer durch İstanbul. İstanbul: Yenilik Basımevi.

Gülersoy, Ç. (1977). Otomobil ile Avrupa Gezi Rehberi. Ankara.

Gülersoy, Ç. (1978). A Guide to İstanbul. İstanbul: Sayılı Basımevi.

Gülersoy, Ç. (1978). Guide d'İstanbul. İstanbul.

Gülersoy, Ç. (1978). Boğaziçi Sorunlar-Çözümler. İstanbul: Erler Matbaacilik.

Gülersoy, Ç. (1979). Guide D'Ístanbul. İstanbul: Yenilik Bas1mevi.

Gülersoy, Ç. (1979). Kapalı Çarşının Romanı. İstanbul: Erler Matbaası.
Gülersoy, C.. (1979). Yıldız Park und Malta Pavillon. İstanbul: Ali Rıza Başkan Güzel Sanatlar Matbaası.

Gülersoy, Ç. (1979). Yıldız Parkı ve Malta Köşkü. İstanbul: Güzel Sanatlar Matbaası.

Gülersoy, Ç. (1979). Parc de Yıldız et Pavillon de Malta. İstanbul. Gülersoy, Ç. (1979). Yıldız Parc and Malta Pavilion. İstanbul.

Gülersoy, Ç. (1979). Turizm Tarihimizden Bir Yaprak: Türkiye'nin Ilk Oteli Hotel d'Angleterre. İstanbul.

Gülersoy, Ç. (1980). Story of the Grand Bazaar. İstanbul: Erler Matbaasi.

Gülersoy, Ç. (1980). Lâle ve İstanbul. İstanbul: Güzel Sanatlar Matbaas1.

Gülersoy, Ç. (1980). Yıldız ve Emirgan Parkları ve Köşkleri. İstanbul.

Gülersoy, Ç. (1981). Pembe Sera'nın Hikâyesi. İstanbul.

Gülersoy, Ç. (1982). Çamlıca'dan Bakışlar. İstanbul: Ali Rıza Başkan Güzel Sanatlar Matbaası.

Gülersoy, Ç. (1982). Eski İstanbul Arabaları. İstanbul: Apa Ofset Basımevi.

Gülersoy, Ç. (1983). Kariye (Chora). İstanbul: Evler Matbaası.

Gülersoy, Ç. (1983). Parc de Yıldız et Pavillon de Malta. İstanbul.

Gülersoy, Ç. (1983). Yıldız Parc and Malta Pavilion. İstanbul.

Gülersoy, Ç. (1983). Yıldız Park und Malta Pavillon. İstanbul.

Gülersoy, Ç. (1983). Yıldız Parkı ve Malta Köşkü. İstanbul.

Gülersoy, Ç. (1983). Yıldız Park und Malta Pauillon. İstanbul: Apa Ofset Basımevi.

Gülersoy, Ç. (1983). Kayıklar. [İstanbul]: Türkiye Turing ve Otomobil Kurum. İstanbul: Güzel Sanatlar Matbaası.

Gülersoy, Ç. (1983). Le Roman du Grand Bazar. İstanbul.

Gülersoy, Ç. (1983). İstanbul Estetiği. İstanbul: Güzel Sanatlar Matbaas1.

Gülersoy, Ç. (1983). Ihlamur Mesiresi. İstanbul.

Gülersoy, C. (1983). Son 400 Yilda Tophane Semti. Ankara: Türk Tarih Kurumu Basımevi.

Gülersoy, Ç. (1983). The Touring and Automobile Association of Turkey 60. Year 1923-1983. İstanbul.

Gülersoy, Ç. (1983). Türkiye'nin Turing ve Otomobil Kurumu 60. yil 1923-1983. İstanbul

Gülersoy, Ç. (1984). Dolmabahçe. İstanbul.

Gülersoy, Ç. (1984). İstanbul'un Anıtsal Ağaçları, I: Rumeli Kavağı Kâğıthane Arası. İstanbul.

Gülersoy, Ç. (1985). Hıdiv'ler ve Çubuklu Kasrı. İstanbul: Apa Ofset Basımevi.

Gülersoy, Ç. (1985). Edirnekapı'sında Bir Örnek. İstanbul.

Gülersoy, Ç. (1985). Hıdiv Kasrı Çubuklu-İstanbul. İstanbul.

Gülersoy, Ç. (1985). Hotel d'Angleterre. İstanbul.

Gülersoy, Ç. (1985). Küçüksu: Çayır-Çeşme- Kasır = Meadow-Fountain-Palace. İstanbul: Apa Ofset Basımevi.

Gülersoy, Ç. (1985). Reklâmlar ve Biz. İstanbul: Apa Ofset Basimevi.

Gülersoy, Ç. (1986). Kariye (chora). İstanbul.

Gülersoy, Ç. (1986). Taksim: Bir Meydanın Hikâyesi. İstanbul: Apa Ofset Matbaacilık.

Cilt $29 \bullet$ Sayı 1 
Gülersoy, Ç. (1987). Batı'ya Doğru. İstanbul: Met/er Matbaası.

Gülersoy, Ç. (1987). Göksu'ya Ağgtt. İstanbul: Aksoy Matbaac1lik.

Gülersoy, Ç. (1987). İstanbul Şarkısı. İstanbul: Aksoy Matbaacilik.

Gülersoy, Ç. (1987). Turing'in Altın Kuralları. İstanbul.

Gülersoy, Ç. (1989). Soğukçeşme Street. İstanbul.

Gülersoy, Ç. (1989). Tramvay İstanbul'da. İstanbul: Evren Ofset.

Gülersoy, Ç. (1989). Kırk Yıl Olmuş. İstanbul.

Gülersoy, Ç. (1990). Dolmabahçe Palace. İstanbul.

Gülersoy, Ç. (1990). Story of the Grand Bazaar. İstanbul: İstanbul Kitaplığı.

Gülersoy, Ç. (1990). Mavi Cami. İstanbul: Ana Basım.

Gülersoy, Ç. (1990). Nasıl Bir İstanbul. İstanbul: Şenar Ofset.

Gülersoy, Ç. (1990). Beyoğlu'nda Gezerken. İstanbul.

Gülersoy, Ç. (1991). The Caique. İstanbul: Temel Matbaacilık.

Gülersoy, Ç. (1991). Taksim: The Story of a Square. İstanbul: Apa Ofset.

Gülersoy, Ç. (1992). Çerağan Sarayları. İstanbul.

Gülersoy, Ç. (1992). The Çerâğan Palaces. İstanbul: Temel Matbacilik.

Gülersoy, Ç. (1993). The Khedives and the Çubuklu Summer Palace. İstanbul: Erler Matbaacillk.

Gülersoy, Ç. (1993). Kız Kulesinin Kitabı. (Ülkü Altınoluk İle Birlikte). İstanbul: Promat.

Gülersoy, Ç. (1993). Tepebaşı: Bir Meydan Savaşı. İstanbul.

Gülersoy, Ç. (1993). Türkiye'ye Bir Işıktı: Turing 1977-1993. İstanbul.

Gülersoy, Ç. (1994). Beşiktaş: Daha Dün. İstanbul: Promat.

Gülersoy, Ç. (1995). İstanbul Maceramız. İstanbul.

Gülersoy, Ç. (1995). Büyük Çamlıca Tepesi, 1980-1995. İstanbul.

Gülersoy, Ç. (1995). Esentepe'ye Veda. İstanbul.
Gülersoy, Ç. (1996). İstanbul Maceramız II. İstanbul.

Gülersoy, Ç. (1997). Büyükada Dün / Yesterday. İstanbul.

Gülersoy, Ç. (1998). Fenerbahçesi. İstanbul.

Gülersoy, Ç. (1999). Yeşil Ev: A Home. İstanbul.

Gülersoy, Ç. (1999). Yeşil Ev: Bir Yuva. İstanbul.

Gülersoy, Ç. (1999). Safranbolu. İstanbul: Promat A.Ş.

Gülersoy, Ç. (1999). Cumhuriyetin Devraldĭ̆ İstanbul'dan Bugüne=Istanbul, from The Birth of The Republic to The Present Day. İstanbul.

Gülersoy, Ç. (1999). Beyoğlu'nun Yitip Gitmiş 3 Oteli. İstanbul.

Gülersoy, Ç. (2000). Hükümet Kapısı Bab-I Ali: Kuruluşundan Cumhuriyet'e Kadar. (M. Nermin Haskan İle Birlikte). İstanbul.

Gülersoy, Ç. (2001). Çelik Gülersoy Albümü 1930-2001. İstanbul.

Gülersoy, Ç. (2001). Büyükada Yetimhanesi. İstanbul.

Gülersoy, Ç. (2001). Çankaya 57. İstanbul.

Gülersoy, Ç. (2002). Atatürk Atatürk. İstanbul: Seçil Ofset.

Gülersoy, Ç. (2003). Pierre Loti ve Dersaadet. İstanbul.

\section{Yayın Tarihi Olmayanlar}

Gülersoy, Ç. Soğukçeşme Sokă̆ı. İstanbul: TTOK.

Gülersoy, Ç. Ayrılış. İstanbul: Çelik Gülersoy Vakfı.

Gülersoy, Ç. Hüzün Yağmuru. İstanbul: Çelik Gülersoy Vakfı.

Gülersoy, Ç. Atatürk Albümü. İstanbul: TTOK.

Gülersoy, Ç. A. Şinasi Hisar. İstanbul: Çelik Gülersoy Vakfı.

Nezih BAŞGELEN, Arkeolog-Editör, Arkeoloji ve Sanat Yayınları, Hayriye cad. Cezayir Sok., Mateo Mratoviç Apt., No:5/2, 34425, Beyoğlu, İstanbul.

E-posta: nezihbasgelen@gmail.com 